\title{
Detection of Ki-ras and p53 Mutations by Laser Capture Microdissection/PCR/SSCP
}

\author{
Deborah Dillon, Karl Zheng, Brina Negin, and José Costa
}

\begin{abstract}
Summary
Efficient detection of somatic mutations is important for the development of clinical molecular diagnostic assays. However, the detection of somatic mutations in tissue is confounded by dilution of the tumor cell population by normal cells. Laser microdissection allows enrichment for tumor-associated genetic alterations to take place at the level of cell selection, eliminating the need to enrich for mutant alleles after amplification. In this chapter a method is described for somatic mutation analysis using cells acquired by laser capture microdissection.
\end{abstract}

Key Words: Mutation; neoplasm; p53; ki-ras; SSCP.

\section{Introduction}

The efficient detection of somatic mutations is important for the development of clinical molecular diagnostic assays, as well as for tissue-based translational research. Compared with the analysis of germline mutations, the detection of somatic mutations in tissue is confounded by dilution of the tumor cell population with non-neoplastic tissue elements. Currently available mutation detection assays typically require that a relatively large proportion of alleles be mutated or require time-consuming intermediate steps to enrich the polymerase chain reaction (PCR) product for the mutant allele prior to sequencing.

By allowing the separation of cells of interest from complex heterogeneous cell mixtures, laser capture microdissection $\operatorname{LCM}(\mathbf{1}, 2)$ provides an alternate strategy to post-PCR mutant-enrichment steps in somatic mutation detection assays. Laser microdissection allows enrichment for tumor-associated genetic 
alterations to take place at the level of cell selection, eliminating the need to enrich for mutant alleles after amplification. Using LCM, clonal mutations can usually be detected and sequenced directly from original PCR products without band-cutting and reamplification for mutant enrichment (3). This strategy is particularly effective for assaying genes with a limited number of expected mutation sites (such as ras genes), but can also be used for genes with a broader range of possible mutation sites. In the latter case, careful exclusion of adjacent non-neoplastic cells during microdissection is critical to optimize the percentage of mutated tumor cell alleles for detection.

Following PCR, amplification products can be either sequenced directly or further screened by single-strand conformational polymorphism (SSCP) analysis $(4,5)$ to focus sequencing efforts on exons most likely to contain mutations. In SSCP analysis, mutations result in altered migration of the amplified mutant alleles relative to the amplified wild-type alleles in nondenaturing gels. Exons showing shifted bands are more likely to have mutations than exons showing the wild-type pattern of bands. SSCP also allows visual estimation of the relative contribution of mutant alleles to the total signal. When mutant alleles constitute at least $30 \%$ of the total signal, it is likely that interpretable sequence results can be obtained without further mutant enrichment.

\section{Materials}

\subsection{Reagents}

\subsubsection{Tissue Preparation and Laser Capture Reagents}

1. Xylene, $100 \%$ ethanol, sterile gauze.

2. Hematoxylin, eosin, methyl green, double-distilled $\mathrm{H}_{2} \mathrm{O}$.

3. Proteinase K.

4. 1X PCR buffer: $50 \mathrm{~m} M \mathrm{KCl}, 10 \mathrm{~m} M$ Tris-HCl, pH 8.3 (Perkin Elmer, Foster City, CA).

\subsubsection{PCR Reagents}

1. Sterile double-distilled $\mathrm{H}_{2} \mathrm{O}$.

2. 10X PCR buffer: $500 \mathrm{mM} \mathrm{KCl}, 100 \mathrm{mM}$ Tris-HCl, pH 9.0 (Perkin Elmer).

3. $\mathrm{MgCl}_{2}$ (Perkin Elmer).

4. dNTPs.

5. Oligonucleotide primers (see Table 1).

6. AmpliTaq ${ }^{\circledR}$ Gold DNA Polymerase (Perkin Elmer).

7. Mineral oil.

\subsubsection{Gel Electrophoresis Reagents}

1. Agarose (2:1 NuSieve:LE, FMC Bioproducts, Rockland, ME).

2. 100-bp ladder (Research Genetics, Huntsville, AL). 


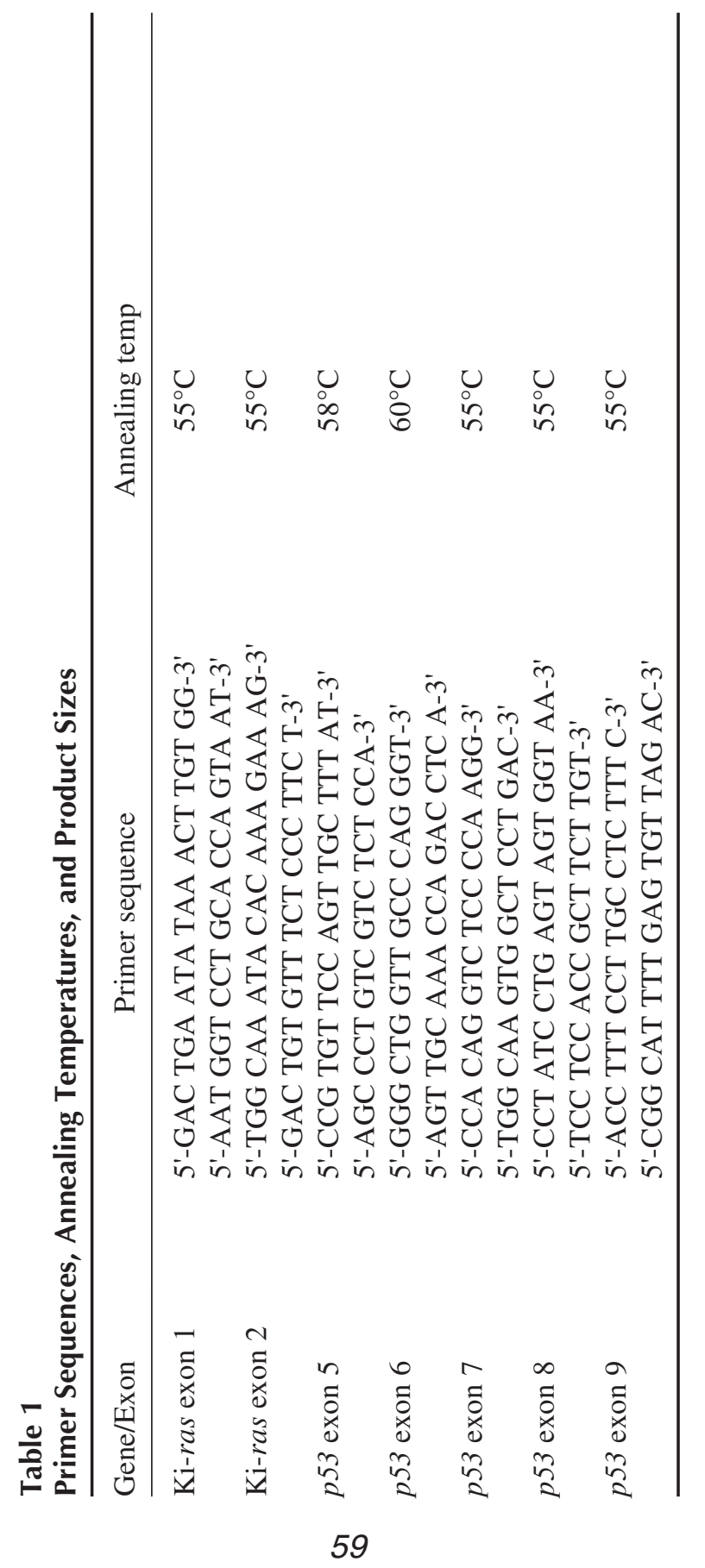


3. Ethidium bromide.

4. $40 \% \mathrm{MDE}^{\mathrm{TM}}$ (mutation detection enhancing) nondenaturing acrylamide gel (FMC Bioproducts).

5. Ammonium persulfate $(10 \% \mathrm{w} / \mathrm{v})$.

6. TEMED.

7. Formamide dye solution: $95 \%$ formamide, $10 \mathrm{mM} \mathrm{NaOH}, 0.05 \%$ xylene cyanol, $0.05 \%$ bromophenol blue.

8. 0.5X TBE gel running buffer: $45 \mathrm{~m} M$ Tris-borate, $1 \mathrm{~m} M$ NaEDTA, pH 8.3.

9. SYBR Green II (Molecular Probes, Eugene, OR).

10. TE: $5 \mathrm{~m} M$ Tris-HCl, $0.5 \mathrm{~m} M$ EDTA, $\mathrm{pH} 7.4$.

\subsection{Equipment}

\subsubsection{Equipment for Tissue Preparation and LCM}

1. Plain (noncoated, noncharged) glass slides.

2. Microtome, forceps, picks, brushes, water bath.

3. Coplin jars for staining setup.

4. Laser capture microscope (Arcturus Engineering, Mountain View, CA).

5. Standard or high-sensitivity caps (Arcturus Engineering).

\subsubsection{Equipment for PCR Amplification}

1. Thermocycler.

\subsubsection{Equipment for SSCP}

1. Heat block maintained at $95^{\circ} \mathrm{C}$.

2. $160 \times 140 \times 0.75 \mathrm{~mm}$ vertical gel apparatus (Hoefer Scientific SE600; Hoefer Scientific Instruments, San Francisco, CA), $18^{\circ} \mathrm{C}$ constant temperature.

3. Power supply.

4. Digital imager (Alpha-Innotech IS1000, San Leandro, CA) equipped with SG3 filter.

\section{Methods}

\subsection{Tissue Preparation and Laser Microdissection}

1. Using a microtome, cut several $5-\mu \mathrm{m}$ sections of each formalin-fixed, paraffinembedded tissue block and mount onto noncoated, noncharged plain glass slides, with thorough microtome decontamination prior to cutting each case (see Note 1). The clear part of the glass should not be touched with hands or fingers at any point in the procedure.

2. Stain the first section of each group of slides using a standard hematoxylin and eosin protocol, coverslip, and use as a reference for tissue morphology in later steps.

3. Stain the remaining sections with methyl green or eosin alone for subsequent microdissection (see Note 2).

4. Capture cell population of interest following manufacturer's protocols (see www.arctur.com for PixCell laser microscopes). 500-1000 30- $\mu$ m captures are 
generally adequate for obtaining 20-60 ng of DNA for mutation analysis (depending on the quality and type of fixation of the target tissue). This may be obtained on a single standard cap, generally requiring no more than $15 \mathrm{~min}$ of microdissection time, except in cases with difficult histology. Duplicate capture of sample onto two caps should be obtained for confirmation of results and to minimize potential contamination artifacts (see Note 3). Figure 1 shows an example of the selective capture of invasive colonic adenocarcinoma cells in a formalin-fixed, wax-embedded tissue sample stained with methyl green.

\subsection{DNA Extraction and PCR Amplification}

\subsubsection{Lysis and Digestion}

1. Place $50 \mu \mathrm{L}$ of DNA extraction buffer $(5 \mathrm{mg} / \mathrm{mL}$ proteinase $\mathrm{K}$ in $50 \mathrm{mM} \mathrm{KCl}$, $10 \mathrm{~m} M$ Tris- $\mathrm{HCl}, \mathrm{pH} 8.3$ ) in $0.5-\mathrm{mL}$ microfuge tubes and cap each tube with a captured sample.

2. Incubate inverted sample at $37^{\circ} \mathrm{C}$ overnight.

3. Heat lysate at $95^{\circ} \mathrm{C}$ for $8 \mathrm{~min}$. Lysate may be used directly into PCR without further purification, using 500-1000 cell equivalents into each $30-\mu \mathrm{L}$ PCR reaction (see Note 4).

4. Store lysate or purified DNA at $4^{\circ} \mathrm{C}$.

\subsubsection{Amplification of Ki-ras and $\mathrm{p} 53$}

1. Amplify exons individually using flanking primers (Table 1). Set up PCR reactions in a total volume of $30 \mu \mathrm{L}$, containing $0.5 \mu \mathrm{M}$ of each primer, $250 \mu \mathrm{M}$ of each dNTP, $50 \mathrm{mM} \mathrm{KCl}, 10 \mathrm{~m} M$ Tris- $\mathrm{HCl}(\mathrm{pH} 8.3), 2.0 \mathrm{mM} \mathrm{MgCl}$, and $0.8 \mathrm{U}$ of AmpliTaq $^{\circledR}$ Gold DNA polymerase (see Note 5). For each specimen, two independent amplification reactions should be performed, containing 5-10 ng purified DNA (or 500-1000 cell equivalents, by calculation) from each of the laser captured samples. TE-only and wild-type controls (human placenta) should be included with each reaction (see Note 6).

2. Following a $12-$ min denaturation at $95^{\circ} \mathrm{C}$, subject mixtures to 40 cycles $\left(95^{\circ} \mathrm{C} / 30 \mathrm{~s}\right.$, $55^{\circ} \mathrm{C} / 45 \mathrm{~s}$ [Ki-ras exons 1 and 2, p53 exons 7-9; see Table 1 for other annealing temperatures], $72^{\circ} \mathrm{C} / 45 \mathrm{~s}$ ) with a final extension at $72^{\circ} \mathrm{C}$ for $10 \mathrm{~min}$.

3. Amplification products (see Table $\mathbf{1}$ for amplicon sizes) should be verified and quantity visually estimated on $3 \%$ agarose gels using a 100-bp ladder and staining with ethidium bromide.

4. Store amplification products at $4^{\circ} \mathrm{C}$ until further analysis by SSCP.

\subsection{Single-Strand Conformational Polymorphism Analysis}

1. Denature 30-ng aliquots of PCR product in $1-5 \mathrm{X}$ volume of formamide dye at $95^{\circ} \mathrm{C}$ for $5 \mathrm{~min}$.

2. Chill samples immediately on ice.

3. Load samples into rinsed wells of $40 \% \mathrm{MDE}^{\mathrm{TM}}$ nondenaturing acrylamide gels and perform electrophoresis in $0.5 \mathrm{X} \mathrm{TBE}$ at $500 \mathrm{~V}$ for $3.0 \mathrm{~h}, 18^{\circ} \mathrm{C}$ constant temperature (Hoefer Scientific SE600 $160 \times 140 \times 0.75 \mathrm{~mm}$ vertical gels). 

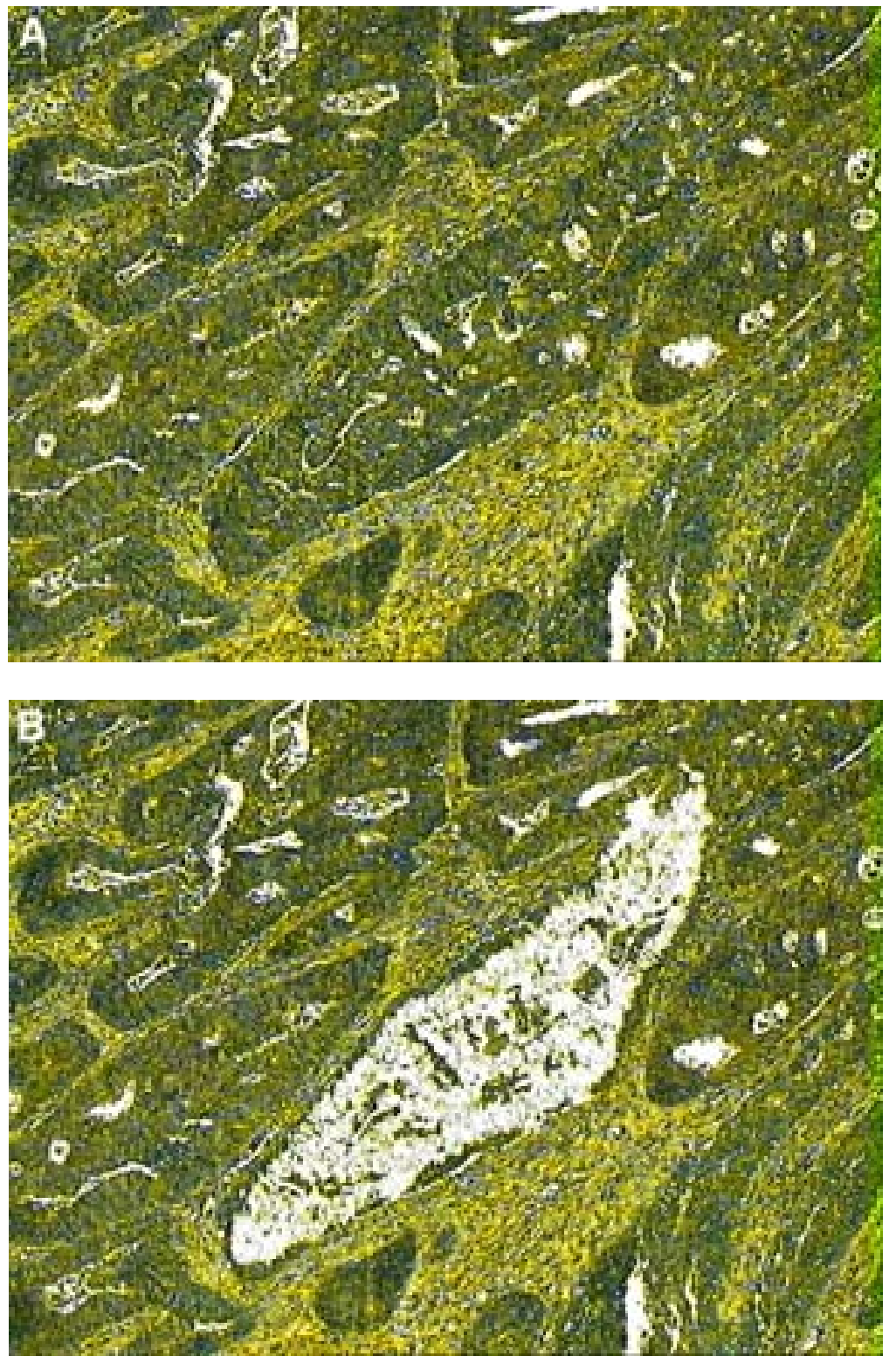

Fig. 1. Laser-capture microdissection of colorectal carcinoma. Sections of formalin-fixed, wax-embedded colorectal adenocarcinoma are stained with methyl green and positioned for laser capture (A). Tumor cells are selectively captured (B). Captured cells can be visualized on the cap (C). (Reprinted from ref. 3 with permission from Elsevier.) 


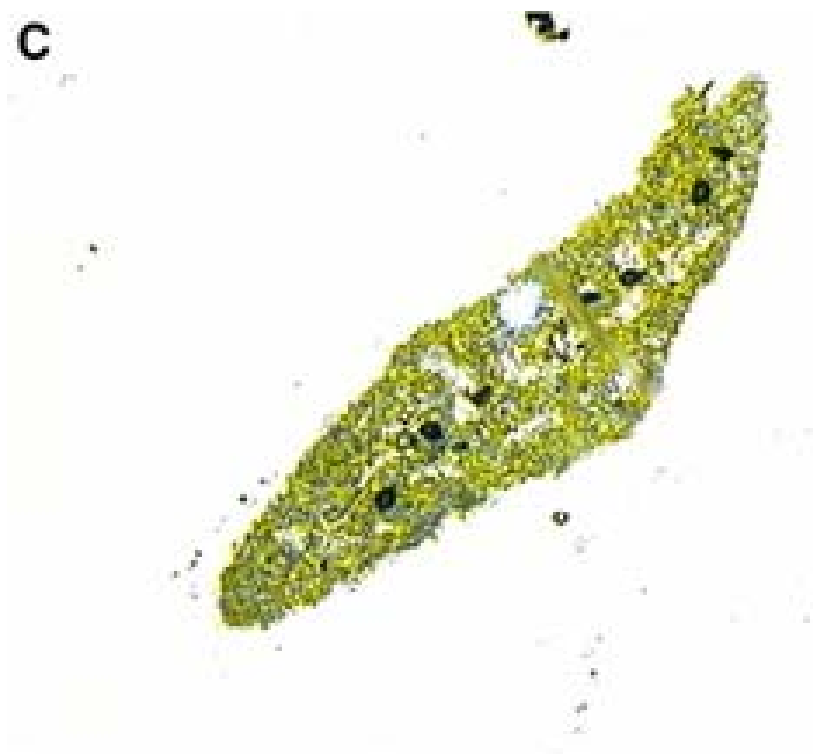

4. Stain gels for 20 min with gentle agitation and light protection using a 1:10,000 dilution of SYBR Green II in TE.

\subsection{Image Collection and Interpretation}

Using $254 \mathrm{~nm}$ ultraviolet transillumination, collect images through an SG3 filter on a digital imager. Mutated alleles show migration patterns different from the wild-type alleles (see Note 7). Relative mutant contribution can be estimated by densitometry of mutant to wild-type bands on the digital gel image. Figure 2 shows representative gel images comparing the SSCP patterns from laser-capture microdissected tissues with hand-microdissected tissues and cut, reamplified aberrantly migrating bands. In the three examples shown, there is enrichment on SSCP in the laser-microdissected samples for the aberrantly migrating bands and in the sequences for the associated mutation. In Case A, there is a Ki-ras codon 13 mutation (GGC $\bullet$ GAC; Gly Asp); in Case B, there is a Ki-ras codon 12 mutation (GGT AGT; Gly Ser); and in Case C, there is a p53 exon 5 mutation at codon 179 (CAT $\bullet$ GAT; His Asp).

In most cases in which laser microdissection can effectively separate the cell population of interest from potentially contaminating cell populations, mutations can be identified and verified by direct sequence analysis of the PCR product. However, SSCP may be used to focus sequencing efforts on exons 

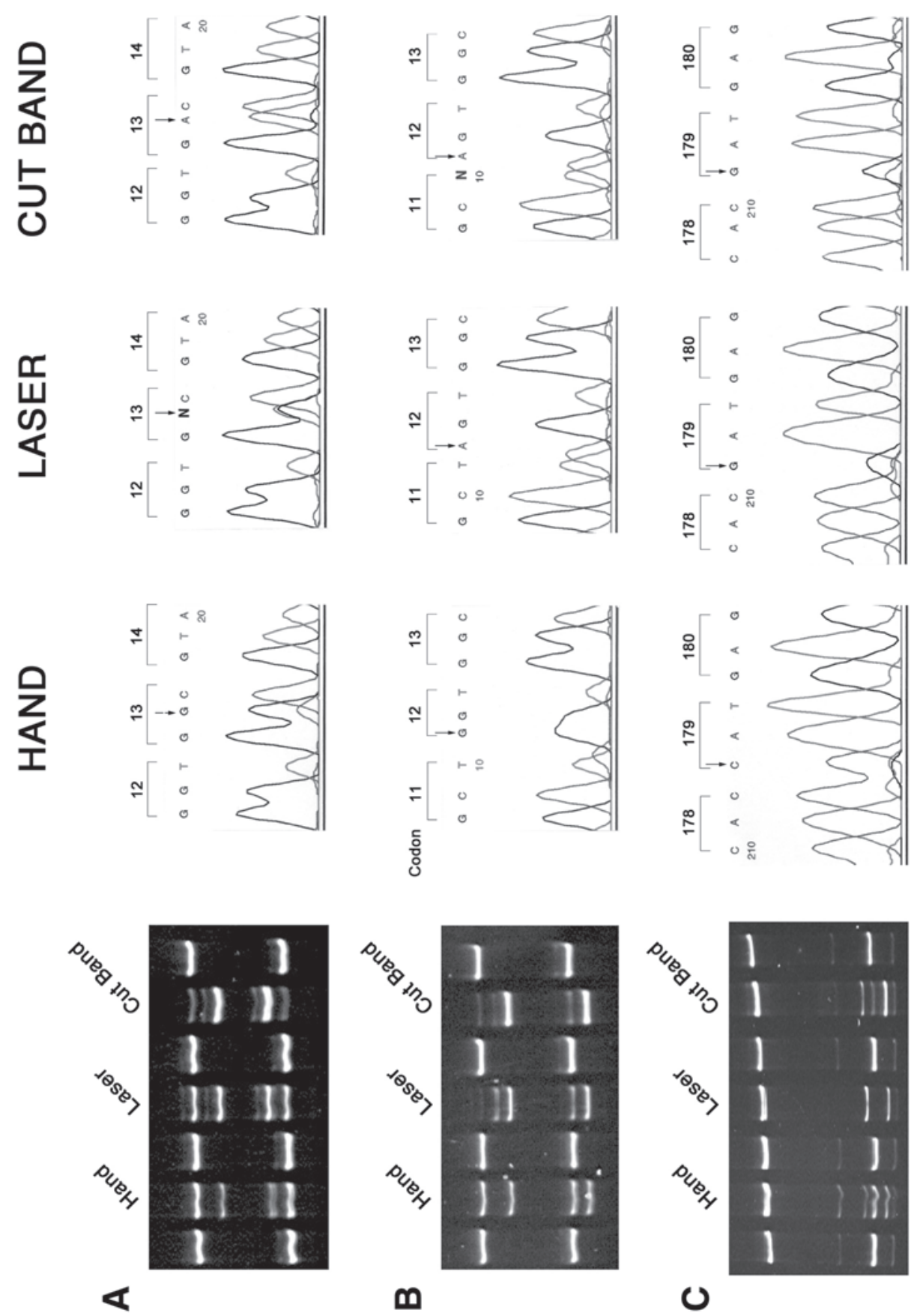
most likely to contain mutations, based on the presence of shifted bands. This is especially useful in cases in which microdissection is difficult due to very small numbers of the cells of interest and/or extensive infiltration of the cells of interest with another cell population (see Note 8).

\section{Notes}

1. To prevent cross-contamination, microtome surfaces must be thoroughly decontaminated prior to sectioning each new tissue block. Thoroughly clean the microtome stage and chuck of all excess material using xylene on sterile gauze, followed by $100 \%$ ethanol. Forceps, picks, and brushes should also be cleaned. A new knife blade or new section of the knife blade should be used for each block. The water bath should also be thoroughly cleaned with xylene, then ethanol, with a final rinse in distilled water. The water bath should then be filled with distilled water. Glue or other adhesives should not be used in the water bath. Frozen tissue blocks may also be used, in which case similar decontamination of the cryostat should be performed.

2. Eosin alone can be used satisfactorily to stain most tissues for microdissection. In our experience, there is a slight improvement in DNA yield with methyl green staining; however, its use is not justified except in cases in which the cell population of interest is very limited. Whichever stain is used, the staining process should end with at least $5 \mathrm{~min}$ in xylene.

3. It is essential to visually monitor the effectiveness of tissue lift during the capture stage, as inefficient capture will lead to failure of subsequent mutation detection procedures. High ambient humidity or failure to adequately dry the tissues during pre-LCM processing are the major causes for inability to capture selected tissue. Optimal humidity for LCM is below $30 \%$. Tissues that are too dry, on the other hand, may result in additional nonspecific lift of surrounding tissues. Additional troubleshooting suggestions for poor tissue lift are available on the Arcturus web site (www.arctur.com).

4. The number of cell equivalents can be calculated for the total lysate sample by multiplying the average number of cell profiles in each $30-\mu \mathrm{m}$ capture by the number of captures. We generally divide the number of visible cell profiles in

Fig. 2. SSCP gels and sequencing results comparing hand- and laser-microdissected samples for detection of mutations in Ki-ras and p53. Lanes 1, 3, 5, and 7 show the wild-type pattern (human placenta) for Ki-ras exon 1 (Cases A and $\mathbf{B}$ ) and $p 53$ exon 5 (Case $\mathbf{C}$ ). In each case, the intensity of the aberrantly migrating mutant bands is stronger in the laser-captured sample (lane 4) than in the hand-microdissected sample (lane 2). The reamplified cut band from the hand-microdissected sample (lane 6) shows similar shifted bands and is included for comparison. Sequences from the handmicrodissected, laser microdissected, and cut bands from the hand-microdissected are seen to the right of each gel with position of the altered bases noted (arrows). (Adapted and reprinted from ref. 3 with permission from Elsevier.) 
each capture by two to compensate for the effect of nuclear truncation in $5-\mu \mathrm{m}$ sections. Alternatively, the DNA may be further purified using standard methods, or any one of a number of commercial kits. Purified DNA should be quantitated and 5-10 ng used in genotyping reactions. The use of limiting amounts of template facilitates the production of PCR artifacts and may result in the detection of artifactual mutations.

5. $1.5 \mu \mathrm{L}$ Rediload $^{\mathrm{TM}}$ (Research Genetics, Huntsville, AL) may be added prior to amplification to facilitate visualization of reagents and products.

6. Standard precautions should be taken to avoid generation of PCR artifacts. All reagents, pipets, and working areas must be clean and free of contamination, with strict segregation of pre- and post-PCR areas. Pipet tips must contain an aerosol barrier to minimize cross-contamination. Use of two no-template controls are recommended: one to be closed prior to opening of any test samples for verification of reagent purity and one to be closed following addition of DNA to all sample tubes for procedural control. All reactions should be performed in duplicate.

7. Mutations result in conformational change of the renatured single-stranded PCR product, which then shows differential migration in nondenaturing gels (i.e., "shifted" bands). Sensitivity of this assay for the detection of mutations in Ki-ras has been established by analysis of serial dilutions of mutant cell line DNA. These studies demonstrate detection of less than $0.5 \%$ mutated alleles in a background of wild-type DNA (6).

8. In the small number of cases in which shifted bands are strong and reproducible, yet no mutation is detected by sequencing, sequence analysis of reamplified bands cut from MDE gels may be performed. In this case, the shifted bands can be excised from MDE gels using a sterile blade, with subsequent elution of DNA by incubation for $5 \mathrm{~min}$ at $55^{\circ} \mathrm{C}$ in $\mathrm{TE}$, and reamplification using the same primer sequences. The reamplified bands can then be gel-purified, bound to NA45 DEAE membrane, and eluted with $1 M \mathrm{NaCl}$ in TE and reprecipitated in ethanol prior to sequencing. In our experience, it is rarely necessary to do this when the DNA is obtained by laser microdissection; however, it remains an option for confirmation purposes.

\section{Acknowledgments}

We are grateful to Mr. Chuck Frederick, Mr. Amos Brooks, and Ms. Mary Helie for expert advice and technical assistance in optimizing the tissue preparation and staining protocols for laser capture microdissection.

\section{References}

1 Emmert-Buck, M. R., Bonner, R. F., Smith, P. D., et al. (1996) Laser capture microdissection. Science 274, 998-1001.

2 Bonner, R. F., Emmert-Buck, M. R., Cole, K., et al. (1997) Laser capture microdissection: molecular analysis of tissue. Science 278, 1481-1483. 
3 Dillon, D., Zheng, K., and Costa, J. (2001) Rapid, efficient genotyping of clinical tumor samples by laser-capture microdissection/PCR/SSCP. Exp. Mol. Pathol. 70, 195-200.

4 Orita, M., Iwahana, H., Kanazawa, H., Hayashi, K., and Sekiya, T. (1989) Detection of polymorphisms of human DNA by gel electrophoresis as single strand conformation polymorphisms. Proc. Natl. Acad. Sci. USA 86, 2766-2770.

5. Chaubert, P., Bautista, D., and Benhattar, J. (1993) An improved method for rapid screening of DNA mutations by nonradioactive single-strand conformation polymorphism procedure. BioTechniques 15, 586.

6. Emanuel, J. R., Damico, C., Ahn, S., Bautista, D., and Costa, J. (1996) Highly sensitive nonradioactive single-strand conformational polymorphism detection of Ki-ras mutations. Diag. Mol. Path. 5, 260-264. 